\title{
Expresión gráfica en la enseñanza actual de la arquitectura
}

\author{
Adrián Berdillana Rivera \\ Universidad de Lima, Perú \\ Recibido: 28 de noviembre de 2013 / Aprobado: 10 de diciembre de 2013
}

En la actualidad, el alumno universitario tiene internalizada la cultura del manejo de medios digitales y se ha apropiado de las tecnologías en forma natural. Las nuevas tecnologías generan transformaciones en la construcción del conocimiento y cierta "crisis" en los modelos tradicionales. Todo esto enfatiza la necesidad de conceptualizar la representación en los procesos formativos, pero también en la coexistencia de los procedimientos manual e informático. El primero es el portador de los conceptos, mientras que el segundo lo es de las visualizaciones, los trazados, la producción y la investigación. A cada modo de expresión le corresponde un papel y un espacio específico.

dibujo, representación, expresión gráfica, tecnología digital, docencia

\section{Graphic expression in current architectural education}

Currently, the college student has internalized the culture of managing digital media and has appropriated technologies in a natural way. New technologies generate transformations in the construction of knowledge and certain "crisis" in traditional models. All this emphasizes the need to conceptualize representation in the learning processes, but also the coexistence of manual and computerized procedures. The first is the bearer of the concepts, while the second is of displays, plots, production and research. Each mode of expression corresponds to a specific role and space.

drawing, rendering, graphic expression, digital technology, teaching 


\section{LA EXPRESIÓN GRÁFICA EN ARQUITECTURA}

La formación gráfica del estudiante de arquitectura constituye una auténtica introducción al ejercicio de la arquitectura misma como actividad creativa. Esta idea, con todas sus consecuencias, establece en definitiva un marco de referencia para el estudio más detenido de la interrelación real de las operaciones de percepción, la representación gráfica, el análisis y la interpretación.

Todo esto confirma, entre otras cosas, el carácter absolutamente necesario de la presencia de lo que hoy constituye el Área de Expresión Gráfica, o al menos del contenido del conjunto de sus asignaturas y sus funciones académicas, en el marco de los programas de la Carrera de Arquitectura. Al mismo tiempo, el de estar en condiciones de empezar a comprender la naturaleza de su tarea y el alcance de su misión: una familiarización con el tipo de discurso propio del ejercicio de proyecto.

Así, entendemos el dibujo de arquitectura como un verdadero procedimiento creativo de búsqueda e indagación de ideas arquitectónicas que, a medida que se conciben, se dibujan, y se definen, se plasman en un punto determinado de su proceso de desarrollo.

En este sentido, necesitamos explicitar que durante el desarrollo del proceso de diseño arquitectónico los sistemas gráficos dejan de ser sistemas de representación, ya que la labor no consiste en representar, en dibujar algo presente; si no que adquieren el carácter de sistemas de prefiguración, que posibilitan, anticipar, imaginar una propuesta espacial que por el momento solo existe en el plano gráfico.

Es el dibujo, para la labor de los arquitectos, un instrumento útil para generar imágenes arquitectónicas.

\section{FORMACIÓN GRÁFICA DEL ESTUDIANTE DE ARQUITECTURA}

El dibujo como disciplina, oficio y sistema científico genera su propia dinámica de funcionamiento, regulada por sus leyes específicas; pero también, al mismo tiempo,el dibujo se entiende simultáneamente:

- Como instrumento indispensable para el ejercicio de la arquitectura como actividad o como el propio lenguaje de trabajo del arquitecto.

- Como una disciplina que tiende a la sensibilizacióndela visiónyalenriquecimiento del sentido de la forma y la abstracción; es decir, a la ejercitación y el desarrollo de capacidades básicas relacionadas con el quehacer profesional, vocacionalmente centrado en la práctica del proyecto: visión espacial, capacidad de

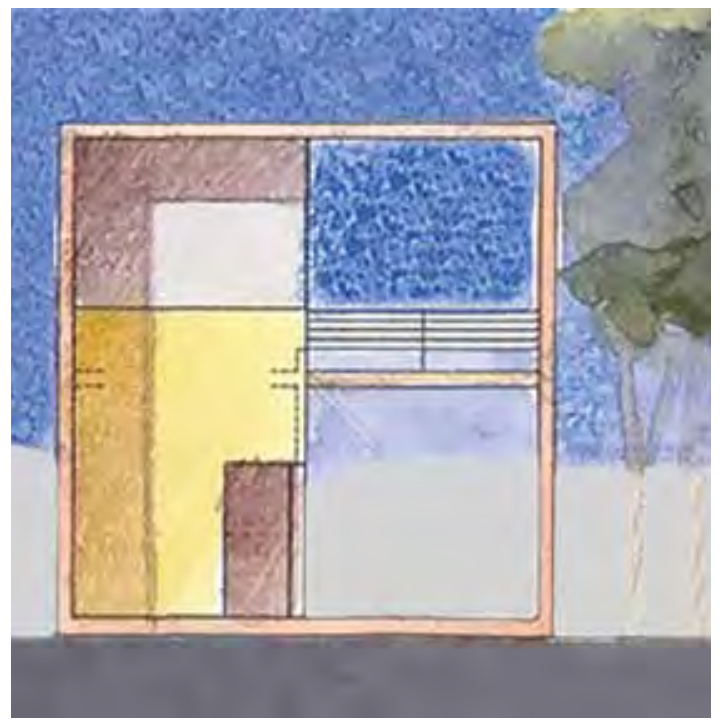

Figura 1.

Elevación. Espacios y geometría. (Al final del proceso, los planos dan instrucciones que permiten la construcción).

Lápiz y color acuarelable.

Dibujo: Área Académica de Comunicaciones. 


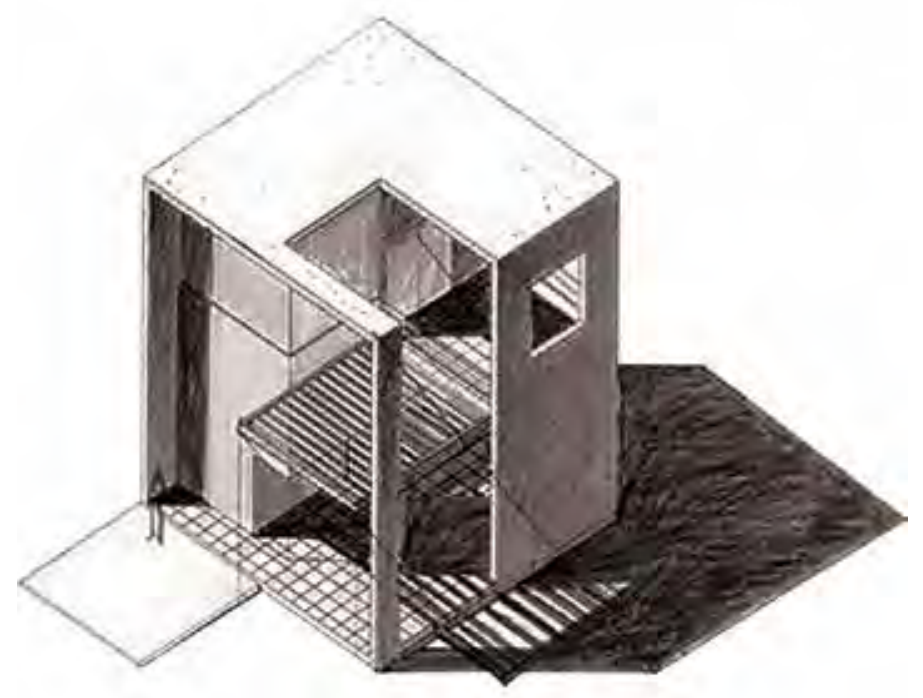

Figura 2.

Isometría. Espacios y geometría. (Entendemos el dibujo de arquitectura como un procedimiento de búsqueda de ideas arquitectónicas). Lápiz y color acuarelable.

Dibujo: Área Académica de Comunicaciones.

análisis e ideación, dominio y control del lenguaje de las formas, soltura y madurez para su posterior manipulación, etcétera.

La representación gráfica requiere una pericia tanto mental como manual (Ching, 1980). Exige del alumno la movilización de buena parte de sus energías mentales y destrezas prácticas: por ejemplo, la comprensión de las relaciones espaciales cuando las formas tridimensionales se plasman en figuras planas (vistas). Además,su representación implica una segunda abstracción, puesto que la transformación de figuras planas a formas tridimensionales suele resultar de extrema abstracción. El aprendizaje de esos procedimientos es el camino para la adquisición de la llamada visión espacial; es decir, la vía para aprender a ver la realidad en orden, imaginar y proyectar transformaciones y variaciones en sus formas.

La adquisición de dicha visión espacial es necesaria para el avance de los alumnos en las tareas de la propia representación, ya que proporciona una serie de técnicas para la representación y transmisión de las cualidades objetivas y abstractas de las formas en el espacio fisico; que al hacerlo enseña a comprenderlas con el objetivo de estar en condiciones de manipularlas. Además, contribuye a la adquisición de determinadas capacidades intelectuales y operativas fundamentales, y suministra a los alumnos la base de ciertas actitudes que estarían en la misma base del ejercicio de la arquitectura como oficio y 


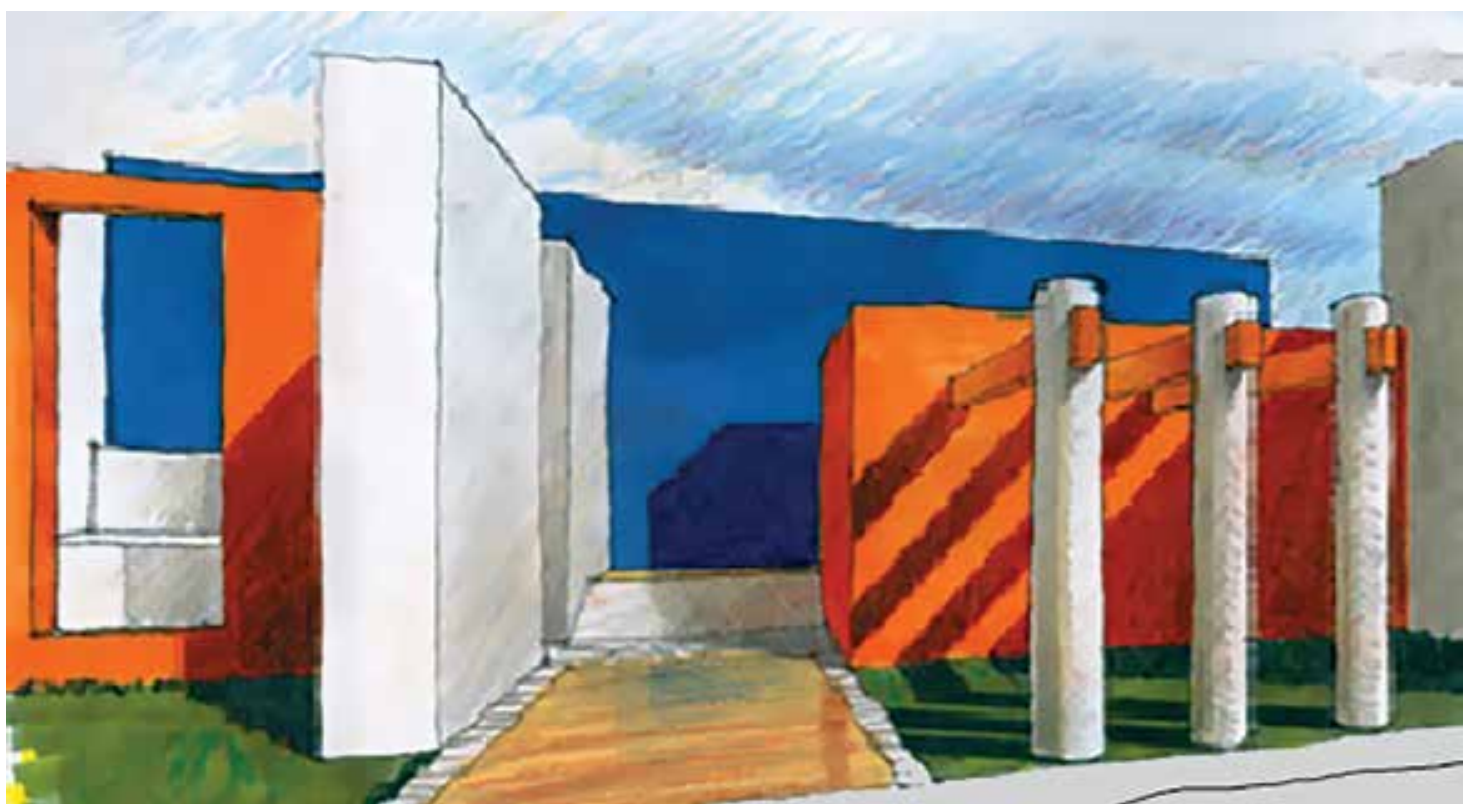

Figura 3.

Perspectiva. Volúmenes, planos y elementos virtuales.

Lápiz y color.

Dibujo: Área Académica de Comunicaciones.

como profesión: actitudes como la racionalidad y el método, la disciplina, la iniciativa, el realismo y el sentido práctico.

\section{LA DOCENCIA DEL DIBUJO}

Enseñar a dibujar es provocar el cambio, modificar una idea, empujar hacia la acción. El conocimiento es asimilado por los alumnos; por sintonía, simpatía o empatía, de ahí la importancia del profesor, la trasmisión de datos supone siempre transformación de la información, el docente se transforma en intérprete, filtro, crítico, porque la enseñanza siempre es creativa. La eficacia del proceso depende también del ánimo del alumno, de sus intereses, de sus motivaciones, de sus prejuicios. El profesor es un lanzador de conceptos, de ideas, de pensamientos propios y ajenos. La concreción del aprendizaje depende del atractivo del profesor que en realidad se expone a diario ante sus alumnos receptores, no solo de información, sino de métodos y maneras. Así se establece una relación profesor-alumno exigente, competitiva, dinámica, flexible, adaptable.

La docencia del dibujo ha de consistir en una ejercitación gráfica insistente de los alumnos, guiados por una continua asistencia; ha de apuntar desde el principio a la necesidad de cuidar al máximo el orden, el rigor y la composición.

Se trata de distribuir y modular con cuidado el marco teórico y el nivel de desarrollo de las explicaciones sobre las actitudes ante el dibujo que desde el 
principio se impone cultivar e inculcar: dichas explicaciones se refieren a asuntos siempre presentes en el ejercicio de representación. Bajo este punto de vista, la expresividad gráfica representa el marco real del aprendizaje de la disciplina del dibujo, y se tiene que comenzar por la identificación de los códigos de representación disponibles en arquitectura, así como de la naturaleza y el modo del acceso a su manejo y dominio.

Los códigos de representación empleados en el dibujo son conceptuales, abstractos, convencionales y universales; son, por tanto, lógicos y racionales, y en definitiva asequibles y susceptibles de ser aprendidos.

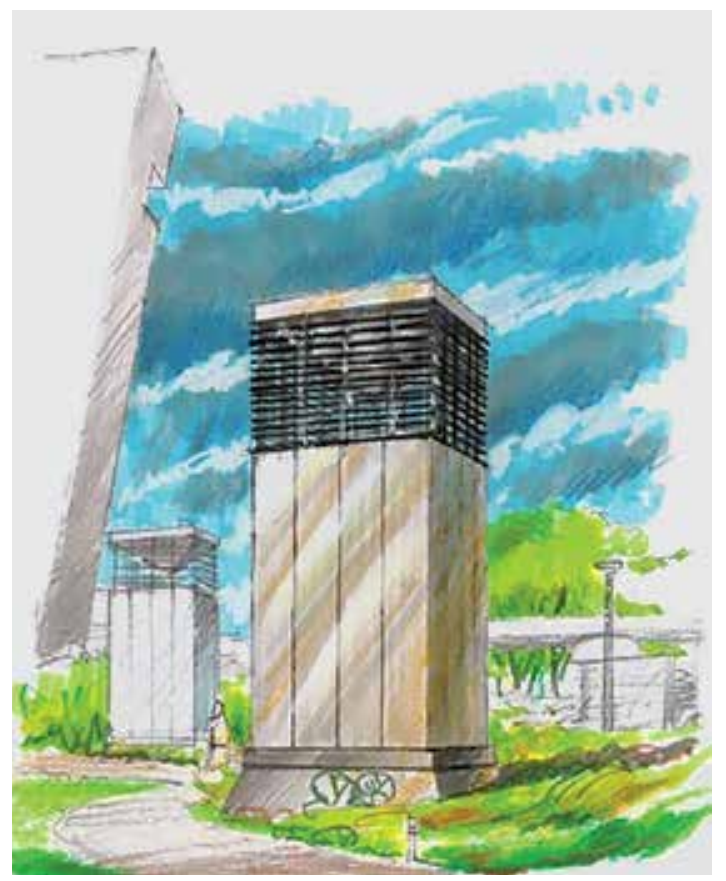

Figura 4.

Perspectiva. Hitos en la Universidad de Lima.

Lápiz y plumón punta pincel.

Dibujo: Área Académica de Comunicaciones.

\section{EL DIBUJO COMO REPRESENTACIÓN CREATIVA}

Las ideas, entidades de la razón y del espíritu, que resultan ser algo bastante borroso, apenas intuido, sin forma consciente en el momento de su aparición; pero que, en el instante en que se traducen las imágenes mentales a imágenes gráficas, ya se las ha representado y se ha comenzado el camino de transformar la idea en un objeto concreto. Dibujar, en arquitectura, no es copiar algo, es crear algo que tiene su propia entidad e identidad y guarda, cuando hay un modelo o referente, una cierta capacidad de evocarlo y representarlo: cuando se trata de un esquema gráfico de tipo proyectivo, de un dibujo que representa algo que todavía está solo en idea y que trata de plasmar con el objetivo a

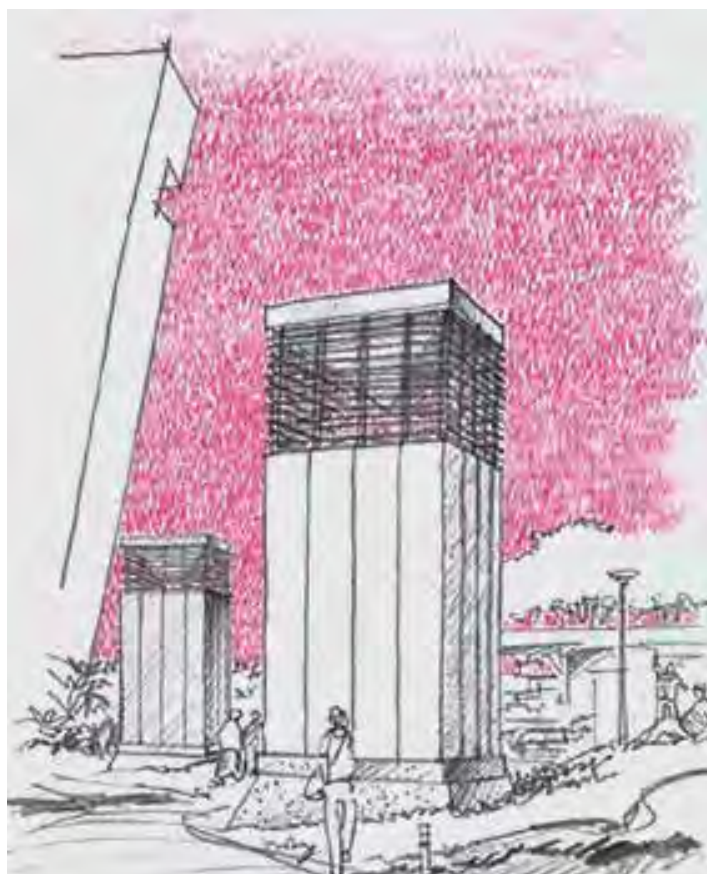

Figura 5.

Perspectiva. Hitos en la Universidad de Lima.

Lápiz y fondo a color en contraste.

Dibujo: Área Académica de Comunicaciones. 
su posterior ejecución o realización, el modelo o referente no solo no está suficientemente claro sino que además no se aclara sino en, a través de, y por el dibujo mismo (Otxotorena, 1992).

Las formas se van definiendo a lo largo de un proceso en cuyo curso los dibujos que lo iluminan y dirigen se rectifican y van madurando paso a paso, a base de medirse sucesivamente con las intenciones que estimulan y las sugerencias que inducen en la mente del arquitecto.

La profesión del arquitecto posee la característica de transmitir ideas, es decir comunicar con su representación; el dibujo es una de las armas que tiene frente al cliente, colega o colaboradores para hacerse entender y convencerlo de su propuesta. Por ejemplo, el croquis es el complemento entre el dibujo básico y la computadora; sin un entrenamiento, el profesional pierde capacidad de convencimiento al no poder transmitir con unos rápidos trazos, explicitar en pocos dibujos, la idea de su proyecto o diseño. Las ideas de un proyecto se suceden en nuestra mente, pero se debe conocer la forma de poder traducirlas al papel, en cualquier momento.

La importancia del dibujo como el croquis se centra en su valoración como recurso en el proceso de diseño, como instrumento de diálogo y monólogo del arquitecto consigo mismo, diálogo en el mundo pedagógico, con los otros profesionales o con el cliente.

De este modo el croquis se convierte en la primera idea en proceso, que significa la "guía y modelo" para cualquier desarrollo posterior; reúne las características de rapidez de ejecución. La importancia del croquis reside esencialmente en las intenciones de fijar, comparar, confrontar y combinar imágenes mentales en el brevísimo momento en que uno explora la realidad para posibilitar que la mano tenga tras de sí la rápida y a veces simultánea asociación con las ideas, anotando de esas ideas lo necesario para representarlas.

\section{PROCEDIMIENTOS INFORMÁTICOS DE DIBUJO}

Lo cierto es que el diseño asistido por computador, CAD (computer-aided desing) por su sigla en inglés, ha ido ocupando una parte importante del espacio usual de las tareas gráficas, $y$ ha hecho pasar a la historia parte de la docencia tradicional en el dibujo, como la práctica del delineado a tinta y la acotación. El CAD exige, de hecho, un lugar claro en el marco de las enseñanzas

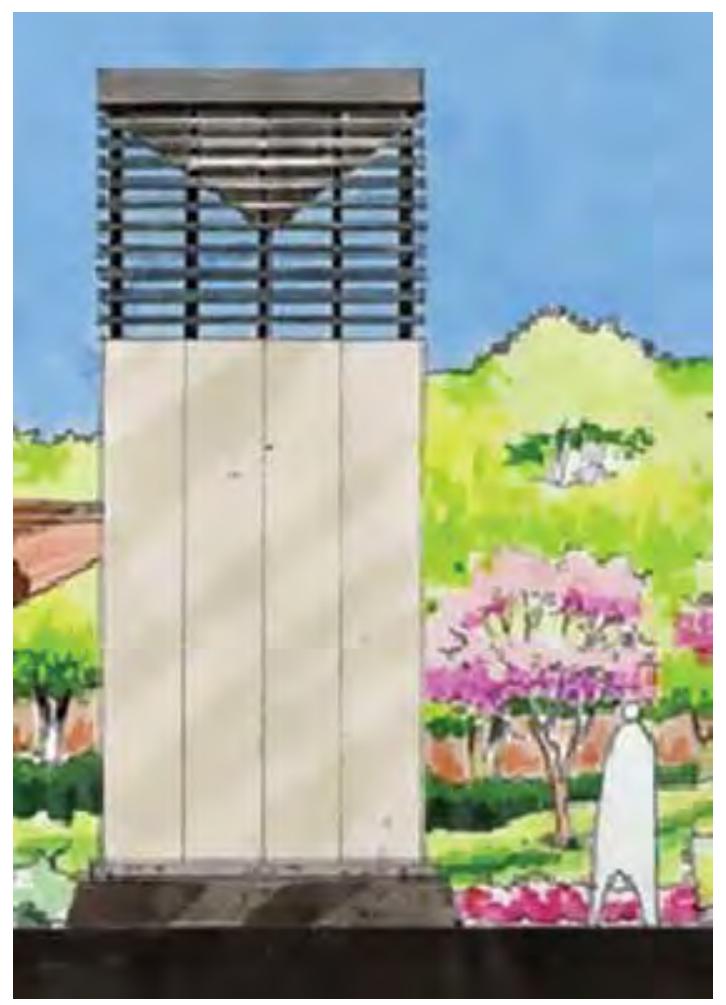

Figura 6

Elevación. Hitos en la Universidad de Lima.

Lápiz y plumón punta pincel.

Dibujo: Área Académica de Comunicaciones. 


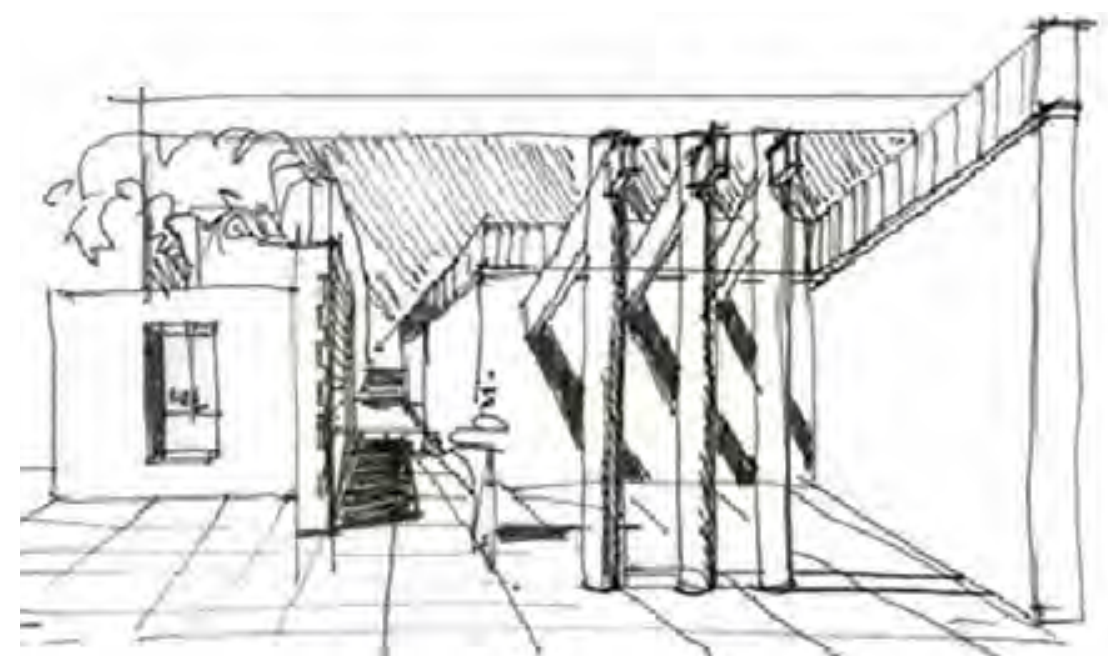

Figura 7

Apunte. Volúmenes, planos y elementos virtuales.

A través de unos primeros trazos difusos, se llevan las ideas

de la mente al papel en blanco. Tinta.

Dibujo: Área Académica de Comunicaciones.

técnicas y el propio replanteamiento global de la formación gráfica; pero no solo por las nuevas facilidades y posibilidades que proporciona en relación con las tareas de dibujo, sino también por la comprensión de la geometría de las formas, ya que se pueden encontrar con él opciones distintas o complementarias de la manera tradicional a los trazados geométricos.

Los medios informáticos, constituyen a todas luces una herramienta de trabajo utilísima, en cuyo manejo y dominio es preciso introducir al estudiante de arquitectura; sin embargo, su aparición está lejos de invalidar completamente la docencia en el dibujo manual impartida en el inicio de la carrera (lo importante es saber las condiciones formativas del dibujo, derivada de su proyectividad específica, cuya necesidad para el proceso de ideación permanece completa eíntegra). El computador, sin duda, ha iniciado el proceso de condicionar la manera como entendemos el mundo y la percepción del lugar que ocupamos en él. Se trata de algo más que un medio pragmático de conseguir un fin, supera la materialidad de un pedazo de hierro y plástico.

El computador y la tecnología digital conforman un binomio virtual de la reconstrucción real y simbólica del mundo en que vivimos (Steele, 2001). Este principio presenta un gran desafío para los arquitectos contemporáneos, ya que los cambios en la representación conlaincorporación delastecnologías electrónicas presuponen un grado comparable de cambios en el quehacer arquitectónico.Todo parece indicar que tales transformaciones tendrán repercusiones significativas en la arquitectura.

En realidad, los nuevos recursos tecnológicos determinan una evolución de la arquitectura que va acompañada de nuevas necesidades en el terreno de su expresión gráfica y también de nuevos medios para llevarla a cabo. En vista de esta situación, es esencial que nos dediquemos a un estudio de cómo las tecnologías en la era de 
la información asociadas con la representación están afectando y afectarán la arquitectura. Eludir esta investigación significaría caer en una utilización ciega de las nuevas tecnologías informáticas o en una negación obstinada y sin sentido de la validez del uso de las computadoras en la arquitectura (Bermúdez, 1995).

\section{CONCLUSIONES}

El dibujo es herramienta imprescindible tanto para el conocimiento del mundo que formamos y transformamos a diario como para pensar y expresar las ideas que queremos construir.

Las manos del arquitecto son la herramienta de su cabeza pensante, son el instrumento que le ayuda a pensar, a materializar las ideas que pretende construir para hacer arquitectura.

La finalidad es la de preparar al estudiante de arquitectura en el terreno del dibujo como tarea directamente relacionada con la actividad profesional, pero en particular en el manejo de ciertas técnicas gráficas que se distinguen por su alto grado de convencionalidad y por su característica capacidad de condensar una información precisa y rigurosa acerca de las formas arquitectónicas, en orden a su definición.

Los arquitectos dependen de las representaciones para diseñar y comunicar la arquitectura. Hay al menos dos razones para esto. Primero, los diseños arquitectónicos no pueden ser desarrollados en escala real por obvios problemas económicos y prácticos.

Segundo, la mente humana tiene claras limitaciones para generar, mantener y transmitir simulaciones correctas de la arquitectura si no cuenta con ayuda externa (como dibujos y maquetas).
Por medio del uso de descripciones que articulan $\mathrm{y}$ comunican las acciones y pensamientos arquitectónicos, los arquitectos no solo resuelven estos dos problemas sino también crean un lenguaje sin el cual el trabajo arquitectónico sería imposible.

Las representaciones arquitectónicas no son solamente herramientas de trabajo sino también el universo del discurso mismo -el espacio conceptual y simbólico- donde el trabajo arquitectónico debe ser desarrollado. Se deduce que si las representaciones son tan esenciales en el trabajo arquitectónico, entonces el tipo de medio $\mathrm{y}$ técnica representacional que uno utilice tiene un efecto directo y duradero en la práctica y pensar arquitectónico.

La profesión arquitectónica debe hacer serios esfuerzos para explorar y adoptar métodos de producción apropiados con las tecnologías digitales existentes.

Para tener éxito en esta empresa se requiere el estudio de la naturaleza y las posibilidades del medio digital como herramienta de trabajo arquitectónico, nuestra atención debería dirigirse a cómo las representaciones electrónicas del presente y del futuro próximo nos ayudarán a llevar adelante aspectos significativos del quehacer del arquitecto en nuevas y más avanzadas formas.

No deberíamos invertir demasiado tiempo en investigar el uso de las computadoras para realizar lo que ya sabemos hacer, aunque sea más rápido, eficiente o atractivo (ejemplo: el dibujo técnico y las perspectivas).

El uso de las tecnologías digitales ha abierto la posibilidad de desarrollar otras metodologías, estrategias para potenciar la percepción espacial durante las diferentes etapas del diseño; facilitando la toma de decisiones, buscando conceptualizar, desarrollar nuevas soluciones 
espaciales, es decir nuevos paradigmas de dibujodiseño contemporáneo durante los procesos en la enseñanza-aprendizaje actual de la arquitectura.

\section{REFERENCIAS}

Berdillana, A. (2008). Tecnologías informáticas para la visualización de la información y su uso en la construcción. Tesis para optar el grado de maestro. Lima: Universidad Nacional de Ingeniería.

Bermúdez, J. (1995). El diseño de experiencias arquitectónicas. Seattle: ACADIA.
Ching, F. (1980). Manual de dibujo arquitectónico. Arquitectura: forma, espacio y orden. México D. F.: s/e.

Otxotorena, J. (1992). Dibujo y arquitectura. Investigación aplicada. Actas del IV Congreso Internacional de Expresión Gráfica Arquitectónica, organizado por la Universidad de Valladolid. Valladolid.

Sanders, K. (1998). El arquitecto digital. Guía para utilizar la tecnología informática al servicio de la arquitectura. Madrid: Universidad de Navarra, Fondo Editorial.

Steele, J. (2001). Arquitectura y revolución digital. México: G. Gili Editores. 